\title{
Combining XRD with Hole-drilling Method in Residual Stress Gradient Analysis of Laser Hardened C45 Steel KOLAŘíK Kamil ${ }^{1, a^{*}}$, PALA Zdenek ${ }^{2, b}$, GANEV Nikolaj ${ }^{3, c}$ and FOJTÍK František ${ }^{4, d}$
}

\author{
${ }^{1}$ Faculty of Mechanical Engineering, University of West Bohemia, Pilsen, Czech Republic \\ ${ }^{2,3}$ Faculty of Nuclear Sciences and Physical Engineering, Czech Technical University in Prague, \\ Prague, Czech Republic \\ ${ }^{4}$ Faculty of Mechanical Engineering,VŠB-Technical University Ostrava, Ostrava, Czech Republic \\ akamil.kolarik@email.cz, bzdenek.pala@fjfi.cvut.cz, cnikolaj.ganev@fjfi.cvut.cz, \\ dfrantisek.fojtik@vsb.cz
}

Keywords: laser hardening, X-ray diffraction, hole-drilling method, depth distribution.

\begin{abstract}
Localized laser hardening of steel surfaces performed with optimal parameters not only hardens the surface layer, but is also capable of generating advantageous hook-like shape of residual stress depth distribution. Upon combining two most common methods of XRD and holedrilling, the residual stresses up to the depth of $3 \mathrm{~mm}$ were analysed for two widths of high-powered diode laser beam. Narrower laser beam generates wider area with compressive stresses and the diffraction technique as compared with hole-drilling method always indicates higher values of compressive residual stress maxima.
\end{abstract}

\section{Introduction}

The advent of high-power diode laser (HPDL) vastly contributed to the ever increasing application of laser hardening in industry, especially when localized hardening is coveted. The fact that the cooling is provided by the surrounding material and the external one is, hence, not needed amply adds to the growing popularity of this hardening treatment. During interaction of laser beam with metal surface, a time variable temperature gradient is present and, consequently, local changes of structure occur. These changes encompass not only phase transitions and surface hardening, but also significant modification of the residual stress fields in the hardened area and adjacent zones. Residual stresses are generated via both phase transformation mechanism and occurrence of inhomogeneous thermal fields. When bcc steels are laser hardened, the effect of phase transformations leads to compressive residual stresses whereas the thermal stresses are dominantly tensile $[1,2]$. Tensile character of thermal residual stresses stems from thermal expansion and ensuing inhomogeneous shrinkage. On the other hand, compressive stresses are generated via phase transformations during cooling from austenite to ferritic or martensitic structure [3]. The interplay of these effects then lead to the final state of residual stress which is of interest especially when dynamic loading of the laser hardened area is to be expected.

In order to determine the residual stress depth distribution experimentally in the industrial praxis, most often, XRD combined with successive layer removal by electro-chemical polishing or holedrilling method is used. In a way, both these experimental approaches embody suitable tools for analysis and control of the hardened area quality due to their semi-destructive character.

This contribution is focused on the issue of mainly residual stress alterations brought about by laser hardening of steels with two laser beam widths. The possibilities of X-ray diffraction and holedrilling techniques in optimization of laser hardening treatment of machine parts are presented. Total depth of $3 \mathrm{~mm}$ was analysed by coupling the XRD measurements with hole-drilling method. In the first layer of $1 \mathrm{~mm}$, both experimental approaches were applied and their results are juxtaposed. For the "last" $1 \mathrm{~mm}$, the hole-drilling was performed in the well created by electrochemical polishing. 


\section{Samples under investigation}

Two sides of medium carbon C45 steel sample of with dimensions $190 \times 50 \times 20 \mathrm{~mm}^{3}$ were analysed (see drawing in Fig. 1). The effect of hardened area width was investigated. Width of hardening area on the first side was $20 \mathrm{~mm}$ and $30 \mathrm{~mm}$ on the other, single laser beam pass was applied. As a source, $3.5 \mathrm{~kW}$ high-power diode laser was used. The laser beam velocity was 3 $\mathrm{mm} / \mathrm{min}$. Hardening temperature was kept at $1200^{\circ} \mathrm{C}$ by pyrometer.

\begin{tabular}{|c|c|c|}
\hline \multicolumn{3}{|c|}{$\overrightarrow{\text { motion of laser beam }}$} \\
\hline$\downarrow_{T}$ & \multicolumn{2}{|c|}{ Non-hardened surface } \\
\hline 1 & 2 Hardened surface & 3 \\
\hline & Non-hardened surf & \\
\hline
\end{tabular}

Fig. 1 Drawing of sample surface laser hardened with $20 \mathrm{~mm}$ wide beam. Numbers 1,2 and 3 denote irradiated surface area during surface XRD measurements in longitudinal (L) and transverse (T) directions and correspond to beginning (area 1), centre (2) and the end (3) of laser beam path.

\section{Experimental techniques}

The crystallographic real structure of hardened, non-hardened and transitional area was qualitatively characterized by $2 \mathrm{D}$ diffraction patterns obtained by using the backscattering arrangement of Debye-Scherrer method. For this purpose, ISO DEBYEFLEX 3003 apparatus, nonfiltered radiation from X-ray tube with chromium anode, cylindrical primary slit with $1 \mathrm{~mm}$ in diameter and image plate detector were employed.

Standard „ $\sin ^{2} \psi$ “ method was performed with vertical $\theta-\theta$ X'Pert PRO diffractometer in $\omega$ arrangement with $\mathrm{CrK} \alpha$ radiation. Because of poor detection efficiency of the $1 \mathrm{D}$ detector for CrK $\alpha$ radiation, point proportional detector was used. The line $\{211\}$ of $\alpha$-Fe phase was measured with the iterplanar lattice spacings computed from maxima of Pearson VII functions fitted to $\mathrm{CrK} \alpha_{1}$ profiles after $\mathrm{CrKa}_{2}$ stripping carried out by Rachinger method. The stresses were computed presuming biaxial state of residual stresses (RS) using Winholtz-Cohen method [4] and X-ray elastic constants $1 / 2 \mathrm{~s}_{2}=5.76 \mathrm{TPa}^{-1},-\mathrm{S}_{1}=1.25 \mathrm{TPa}^{-1}$. To assess cold work, breadths of diffraction line were characterized by Full Width at Half Maximum (FWHM) parameter. In order to analyse the stress gradients beneath the samples surface, layers of material were gradually removed by electro-chemical polishing in the centre of the sample, see area 2 in Fig. 1. Striving to ensure that the position of the irradiated surface does not violate the stringent conditions imposed on $\mathrm{z}$ displacement, laser triangulation with 5 micron accuracy was employed and the sample was mounted on xyz stage with two perpendicular cradles. The approach for correcting the stress values due to successive layer removal proposed by Moore and Evans was not followed [5] due to the fact, that such corrections are comparable with experimental inaccuracies typical of RS determination by XRD, see e.g. [6].

Hole-drilling method was performed using static tensometric apparatus P3500 VISHAY [7]. Sintered carbide milling cutters had $1.8 \mathrm{~mm}$ in diameter and the holes had depth of $2 \mathrm{~mm}$. The detection of released deformations was done by 3 rectangular tensometric rosettes EA - 06-062RE -120 . The stresses were calculating according to ASTM E837-08 [8] and the used Young modulus $200 \mathrm{GPa}$ and Poisson ratio 0.3. Hole-drilling was applied in surface layer with thickness of $1 \mathrm{~mm}$ (in the centre of the hardened area and $2 \mathrm{~cm}$ from the area 2) and also in already electropolished well in area 2. The initial depth of this well was $1.85 \mathrm{~mm}$ from the starting surface and throughout this depth, the XRD measurements were carried out. 


\section{Results}

Microstructure of the hardened area and the adjacent material can be seen on metallographic cross-section in Fig. 2. Moreover, the surface distribution of hardness for $20 \mathrm{~mm}$ thick laser beam is depicted in Fig. 3.

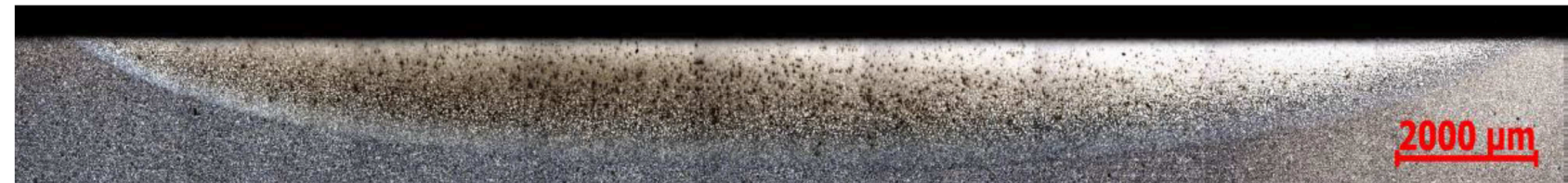

Fig. 2 Microstructure after hardening by $20 \mathrm{~mm}$ wide laser beam seen on metallographic crosssection.

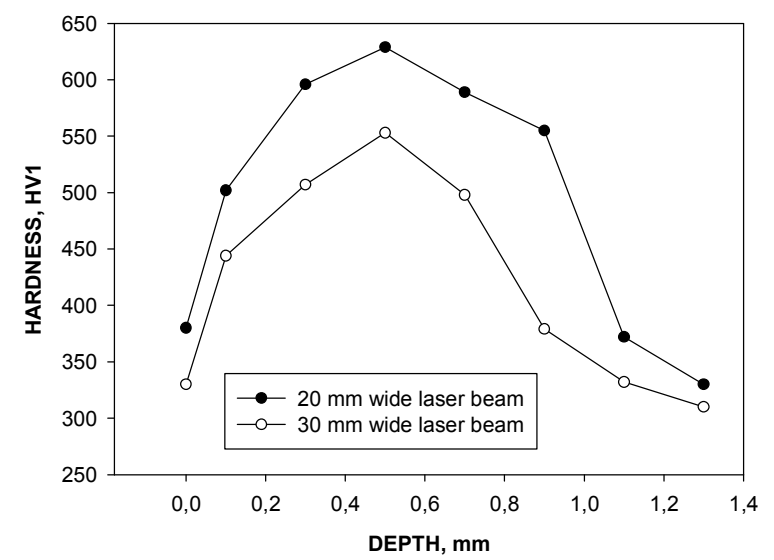

Fig. 3 Depth distribution of hardness (HV30) after hardening with 20 and $30 \mathrm{~mm}$ wide laser beam.

The back-reflection X-ray diffraction patterns, taken before performing the residual stress measurements, correspond to diffraction of the spectral doublet $\mathrm{CrK} \alpha_{1} \alpha_{2}$ on $\{211\}$ crystallographic planes of $\alpha-\mathrm{Fe}$, see Fig. 4. The surface after temperature treatment shows isotropic fine-grained polycrystalline structure, i.e. Debye ring is broad and continuous with homogeneous intensity around its perimeter. In the case of the untreated surface, the Debye ring becomes narrow with a slight indication of discrete diffraction spots located uniformly around perimeter that gives evidence of virtually non-existent preferred orientation. This is the reason why X-ray diffraction can be used for the surface residual stress determination. Selected results of RS and FWHM are in Tab. 1 and in Figs. 5 - 7. Juxstaposition of XRD and hole-drilling results can be seen in Figs. 8 and 9.
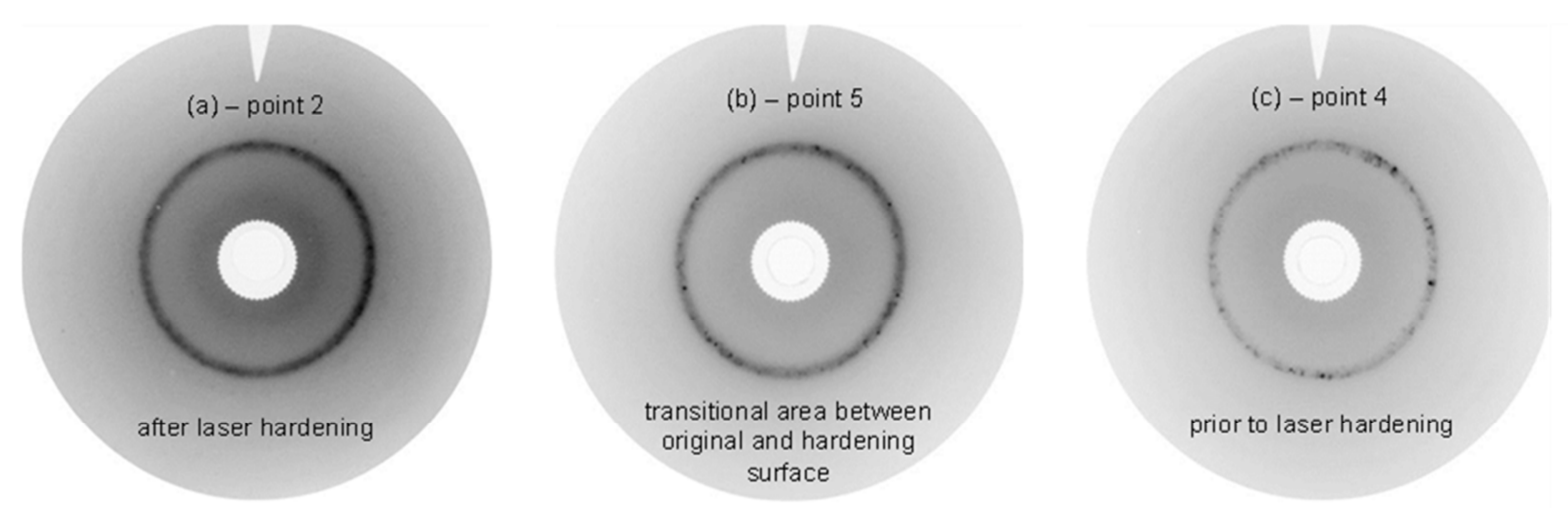

Fig. 4 Back-reflection X-ray diffraction patterns from the surfaces after (a) and before laser hardening (c) and from the transitional area between them (b). Consult Fig. 1 for the assignment of the points. 


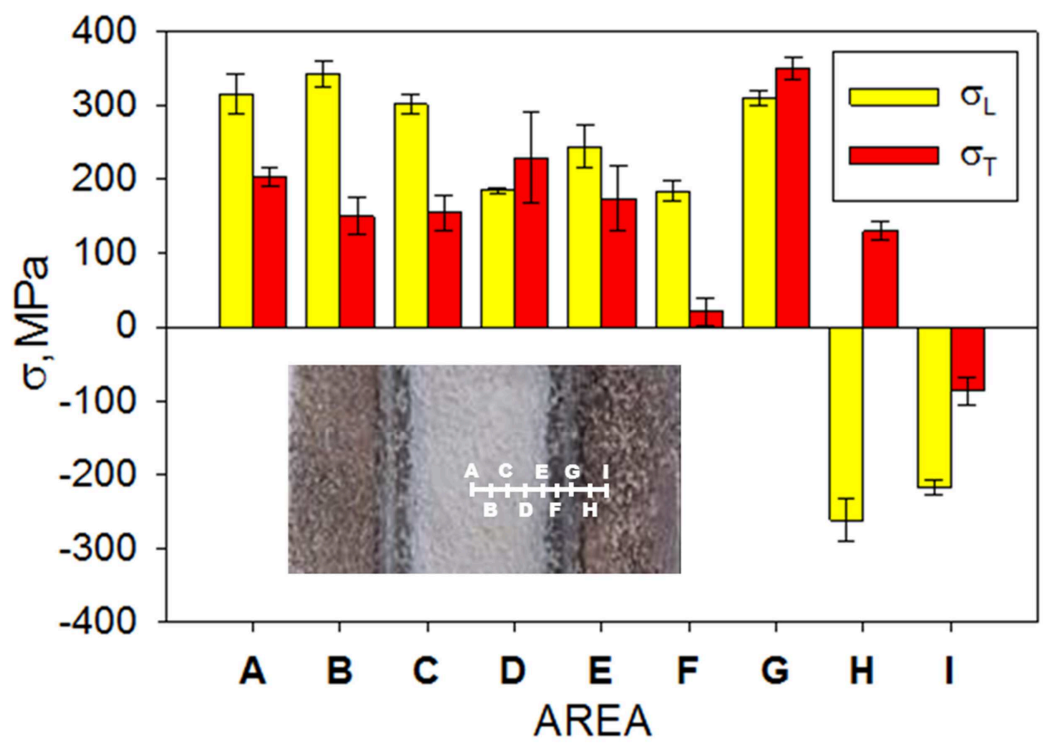

Fig. 5 Surface RS determined by XRD obtained from areas A (hardened) to I (non-hardened), laser beam width was $20 \mathrm{~mm}$.

Tab. 1 Values of surface macroscopic residual stresses $\sigma_{\mathrm{L}}, \sigma_{\mathrm{T}}$ and FWHM of $\{211\} \alpha$-Fe diffraction line determined by XRD obtained from surface hardened by $20 \mathrm{~mm}$ and $30 \mathrm{~mm}$ wide laser beams.

\begin{tabular}{|c|c|c|c|}
\hline $\begin{array}{c}\text { measured area } \\
\text { (lasering area width) }\end{array}$ & $\begin{array}{c}\sigma_{L} \pm \Delta \sigma_{L} \\
{[\mathrm{MPa}]}\end{array}$ & $\begin{array}{c}\sigma_{T}^{ \pm \Delta \sigma_{T}} \\
{[\mathrm{MPa}]} \\
\end{array}$ & $\begin{array}{c}<F W H M> \\
{[\operatorname{deg}]}\end{array}$ \\
\hline $\boldsymbol{I}(20 \mathrm{~mm})$ & $233 \pm 6$ & $116 \pm 3$ & 1.62 \\
\hline $2(20 \mathrm{~mm})$ & $302 \pm 14$ & $143 \pm 5$ & 1.62 \\
\hline $3(20 \mathrm{~mm})$ & $283 \pm 7$ & $124 \pm 3$ & 1.53 \\
\hline $\boldsymbol{I}(30 \mathrm{~mm})$ & $177 \pm 3$ & $235 \pm 2$ & 1.44 \\
\hline $2(30 \mathrm{~mm})$ & $128 \pm 5$ & $172 \pm 3$ & 1.46 \\
\hline $3(30 \mathrm{~mm})$ & $110 \pm 3$ & $203 \pm 4$ & 1.45 \\
\hline
\end{tabular}

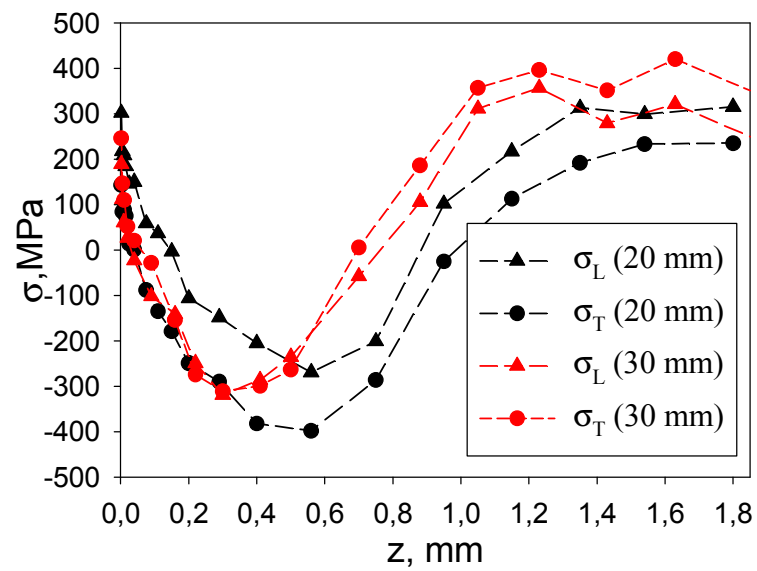

Fig. 6 The depth profiles of RS in surface layers of investigated areas determined by XRD.

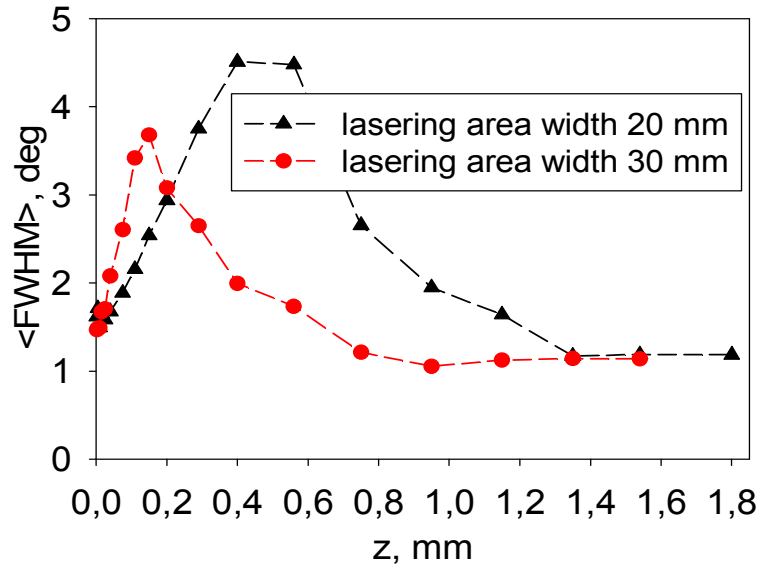

Fig. 7 The depth distributions of $\{211\}$ $\alpha$-Fe diffraction line FWHM parameter. 


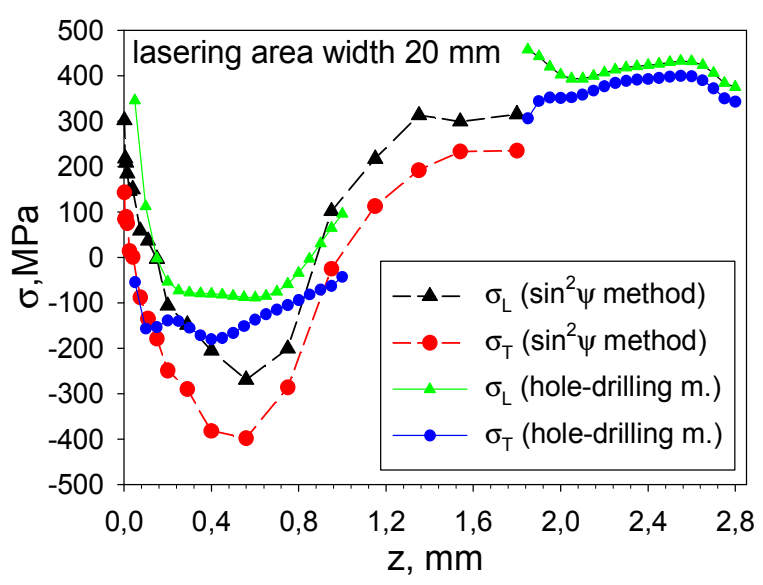

Fig. 8 Depth gradient of residual stresses $\sigma_{\mathrm{L}}$ and $\sigma_{\mathrm{T}}$ determined by both experimental approaches for $20 \mathrm{~mm}$ wide laser beam.

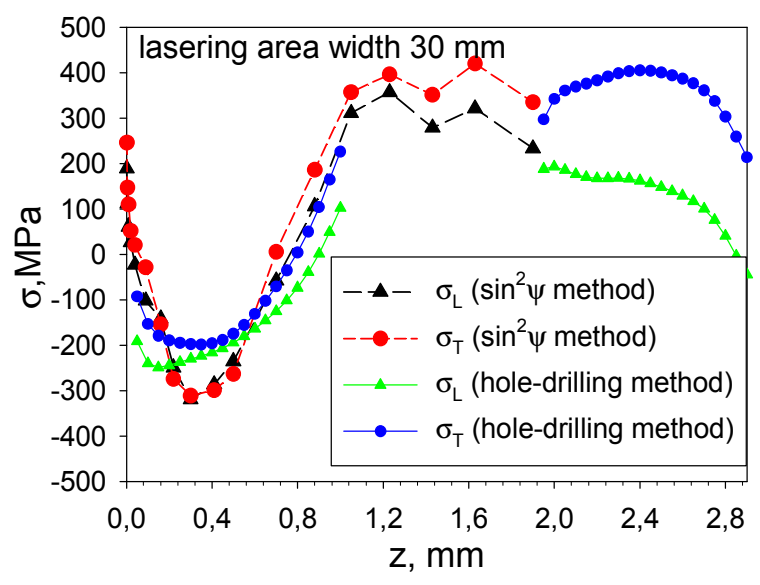

Fig. 9 Depth gradient of residual stresses $\sigma_{\mathrm{L}}$ and $\sigma_{\mathrm{T}}$ determined by both experimental approaches for $30 \mathrm{~mm}$ wide laser beam.

\section{Discussion and conclusions}

XRD results. It was found that both the laser hardened areas with widths of 20 and $30 \mathrm{~mm}$ have tensile surface RS exceeding $100 \mathrm{MPa}$ which is most likely the consequence of dominant inhomogeneous thermal deformations during cooling or even surface layers' partial melting [2] and the compressive effect of phase transformation was, hence, suppressed.

Surface treated with narrower beam size shows higher values of parameter FWHM. Increase of this parameter is due to existence of high concentration of dislocations after laser hardening and smaller crystallite size in structure which corresponds to higher hardness [9, 10] documented in Fig. 3.

RS depth distributions in Fig. 6 show that wider laser beam results in smaller maxima of compressive RS, about $300 \mathrm{MPa}$, which are found in shallower depth about 0.3 beneath the surface. Moreover, RS in both the measured directions are equal within the experimental inaccuracy which indicates equi-biaxial state of RS.

For narrower beam width, the maxima of $\sigma_{\mathrm{L}}$ and $\sigma_{\mathrm{T}}$ are found in larger depth of approx. $0.6 \mathrm{~mm}$ beneath the surface and RS in both the measured directions are not the same, namely $\sigma_{\mathrm{T}}=-400$ $\mathrm{MPa}$ and $\sigma_{\mathrm{L}}=-270 \mathrm{MPa}$.

The shift in the position of RS maxima is also reflected in depth distribution of FWHM parameter in Fig. 7. This indicates that smaller laser beam and, thus, smaller hardened volume, which is more effectively cooled by the adjacent material, results in deeper maxima of RS, thicker layer with compressive stresses and also higher hardness.

During laser hardening, two dominant mechanisms of residual stress generation are present. Phase transformation mechanism during sample cooling that introduces compressive RS and thermal deformation mechanism leading to tensile RS. For the smaller beam size is, therefore, the phase transition mechanism more pronounced in comparison with wider beam.

The RS values (Fig. 5) obtained from surface areas (A - I) correspond to the trend observed for ferritic steel hardened by HPDL described in [11].

Combining the XRD and hole-drilling method results. Depth distributions obtained by both methods are qualitatively similar, i.e. tensile residual stresses on the surface and subsequent decline to compressive stresses followed by increase to tensile stresses in the bulk. The widths of the layer with compressive residual stresses found by both methods are also similar. 
The lack of knowledge about experimental inaccuracies for hole-drilling method does not facilitate determination of how close are the $\sigma_{\mathrm{T}}$ and $\sigma_{\mathrm{L}}$ values for the sample hardened by wider laser beam for which XRD found equi-biaxial state of residual stress.

From the combination of RS depth distributions of both methods it can be seen that the sample hardened by narrower beam exhibits wider (approx. $1 \mathrm{~mm}$ wide) area with compressive stresses followed by wide area with tensile stresses in the bulk (Fig. 8) whereas the sample hardened by wider beam is characterized by narrower area with compressive stresses (approx. $0.7 \mathrm{~mm}$ ) followed by narrower area with tensile stresses in the bulk (Fig. 9).

Diffraction method indicates higher values of compressive residual stresses maxima and it was reaffirmed that hole-drilling method has low sensitivity for surface residual stresses.

Acknowledgments - This research was carried out in the frame of projects NEXLIZ CZ.1.07/2.3.00/30.0038 and FR-TI3/814 of Ministry of Industry and Trade of the Czech Republic.

\section{References}

[1] Pilloz, M., Sahour, C. \& Vannes, B. (1989). Study of the parameters of laser coatings and residual stress field created by these coating. Proceedings of 2 nd Int. Seminar on Surface Engineering with High Energy Beams, Lisbon, (1989), pp. 387-413.

[2] Freitas, M., Fereira, M.S. \& Michaud, H. (1993). Analysis of residual stresses induced by laser processing. Mat. Sci. Eng, Vol. 167, (1993), pp. 115-122.

[3] J. B. Leblond, G. Mottet, J. Devaux, J. C. Devaux, Mathematical models of anisothermal phase transformations in steels, and predicted plastic behaviour, Mater. Sci. Technol., 1 (1985) 815-822.

[4] R.A. Winholtz, J.B. Cohen, Generalised Least-squares Determination of Triaxial Stress States by X-ray Diffraction and the Associated Errors, Aust. J. Phys. 41 (1988) 189-199.

[5] M. G. Moore, W. P. Evans, Mathematical correlation for stress in removed layers in X-ray diffraction residual stress analysis, SAE Trans. 66 (1958) 340.

[6] C.L. Azanza Ricardo, M. D'Incau, P. Scardi, Revision and extension of the standard laboratory technique for X-ray diffraction measurement of residual stress gradients, J. Appl. Cryst. 40 (2007) 675-683.

[7] Information on http://www.vishaypg.com

[8] ASTM E 837 - 08: Determining Residual Stresses by the Hole - Drilling Strain-Gage Method

[9] Benedek, J., Shachrai, A. \& Levin, L. (1980). Case hardening of steel by a CO2 laser beam. Optics and Laser Technology, Vol. 12, (1980), pp. 247-253.

[10] Vilar, R., Colaço, R. \& Almeida, A. (1995). Laser surface treatment of tool steels. Optical and Quantum Electronics, Vol. 27, (1995), pp. 1273-1289.

[11] Kostov V., Bibmeier J., Wanner A., Laser Surface Hardening of Steel: Effect of Process Atmosphere on the Microstructure and Residual Stresses, Mat. Sci. Forum 681 (2011) 321-326. 